\title{
An investigation into the purchasing habits of secondary education pupils at school canteens within Northern Ireland
}

A systematic review of interventions for preventing obesity in children highlighted 'establishing environments and cultural practices within schools that support children eating healthier foods throughout the day' as one of the most effective intervention strategies ${ }^{(1)}$. The objective monitoring of lunchtime food choices facilitated by cashless canteen systems in schools also has significant potential as a key outcome measure in nutrition research. Even though these systems have the potential to track the food purchasing habits of hundreds of school children over a prolonged period of time (which would not be feasible for other dietary assessment methods) little research has been conducted in the area.

This aim of this study was to examine the food purchasing habits of pupils aged 12-13 (year 9) and 17-18 years old (year 14) at the school canteen. Preliminary work was carried out in two secondary schools, one urban and one rural, to improve the till layouts. This enabled more detailed information about food purchases to be captured. Purchasing data from the cashless canteen systems was obtained from each school. This purchasing data for six weeks across April and May was entered into Nutritics dietary analysis package for 115 year 9 pupils and 179 year 14 pupils. Frequency data was analysed as a proportion of all food purchases to determine the most popular food choices made by year 9 and year 14 pupils. Separate analyses took place for each school as the school menus were not standardised.

Table 1 Shows the most and least popular food items purchased in the canteen at the urban and rural school by year 9 and year 14 pupils.

\begin{tabular}{|c|c|c|c|c|c|}
\hline & & \multicolumn{2}{|r|}{ Urban } & \multicolumn{2}{|l|}{ Rural } \\
\hline & & Yr 9 & Yr 14 & Yr 9 & Yr 14 \\
\hline \multirow{4}{*}{$\begin{array}{l}\text { *Most } \\
\text { popular }\end{array}$} & Main & Beef burger $(4.9 \%)$ & Beef burger $(9.3 \%)$ & Beef burger $(10 \cdot 2 \%)$ & Meal deal $(5 \cdot 1 \%)$ \\
\hline & Side & Chips $(11 \cdot 1 \%)$ & Chips $(18.7 \%)$ & Boiled potato $(11.9 \%)$ & Frozen veg $(4.8 \%)$ \\
\hline & Dessert & Custard $(10 \cdot 5 \%)$ & Custard $(22.7 \%)$ & Jelly $(17.9 \%)$ & Custard $(10 \cdot 3 \%)$ \\
\hline & Drink & Water $(21.5 \%)$ & Water $(32 \cdot 0 \%)$ & Fruice pure $(31.9 \%)$ & Fruice pure $(4 \cdot 2 \%)$ \\
\hline \multirow[t]{4}{*}{$\begin{array}{l}\text { *Least } \\
\text { popular }\end{array}$} & Main & $\begin{array}{l}\text { Quiche/pizza/pasta } \\
(0.1 \%)\end{array}$ & Chicken pie $(0.1 \%)$ & $\begin{array}{l}\text { Bubble and squeak/chicken jambalaya/smoked } \\
\text { haddock/lasagne/pork chops/quiche }(0.1 \%)\end{array}$ & Chicken dishes $(0 \cdot 1 \%)$ \\
\hline & Side & $\begin{array}{l}\text { Pasta salad/tossed } \\
\text { salad }(0.05 \%)\end{array}$ & $\begin{array}{l}\text { Curry sauce/potato salad } \\
(0.05 \%)\end{array}$ & $\begin{array}{l}\text { Baked potato with chicken and bacon/roast potato } \\
(0.1 \%)\end{array}$ & $\begin{array}{l}\text { Baked potato with chicken } \\
\text { and veg }(0 \cdot 1 \%)\end{array}$ \\
\hline & Dessert & $\begin{array}{l}\text { Ice cream/wafers } \\
(0.3 \%)\end{array}$ & $\begin{array}{l}\text { Apple crumble/rice-pudding/ } \\
\text { wafers }(0.3 \%)\end{array}$ & Trifle $(0.9 \%)$ & Queen cake $(1.7 \%)$ \\
\hline & Drink & Tea/coffee/ $(0 \cdot 05 \%)$ & Milkshake $(0.7 \%)$ & Hot chocolate $(0 \cdot 1 \%)$ & Milkshake $(1.3 \%)$ \\
\hline
\end{tabular}

*Proportion (\%) of food/beverages purchased out of the total number of purchases per category.

The most and least popular food choices differed between the urban and rural school, with the exceptions being that beef burgers were the most popular main for year 9 pupils in both schools, custard was the most popular dessert for year 14 pupils in both schools, and milkshake was the least popular drink for year 14 pupils in both schools. Within each school, year 9 and year 14 pupils differed in the least popular food choices and this was also true for the most popular foods purchased in the rural school but not the urban school.

The current study provides new evidence regarding the use of $\mathrm{CC}$ data to monitor pupil's purchasing habits and suggests changes in food purchasing habits between year 9 and year 14 pupils that would be worthy of investigation in a larger more representative sample of schools to help inform future dietary interventions in the school setting.

1. Waters E, de Silva-Sanigorski A, Hall BJ et al. (2011) Interventions for preventing obesity in children. Cochrane Database Syst Rev 12, CD001871. 